\title{
Halogen Bonding as a New Driving Force for Layer-by- Layer Assembly
}

\author{
Fang Wang, Ning Ma, Qiuxia Chen, Wenbin Wang, and Liyan Wang*
}

Key Lab for Supramolecular Structure and Materials, Jilin University, Changchun 130012, China

\section{Supporting information}

\section{Methods}

NMR spectra were recorded on a Bruker Avance-500 NMR spectrometry (500 MHz). The molecular weight of PIPBA was measured by gel permeation chromatography (Waters 410) with polystyrene as calibrated standard. UV-vis spectra were collected on a Perkin Elmer Lambda 800 UV-vis spectrometry. Quartz crystal microbalance (QCM) measurements were carried out on KSV QCM-Z500 using $9 \mathrm{MHz}$ quartz resonators. X-ray reflectivity (XRR) measurements were performed on a Bruker D8 Tools instrument using $\mathrm{Cu} \mathrm{K \alpha}$ radiation $(\lambda=0.15406 \mathrm{~nm}$ ) at $40 \mathrm{kV}$ and $40 \mathrm{~mA}$. Atomic force microscopy (AFM) images were recorded on Dimension 3100 (Digital Instruments) using silicon cantilevers at tapping mode. X-ray photoelectron spectroscopy (XPS) were obtained on Thermo ESCALAB250 instrument with $\mathrm{Al} \mathrm{K} \alpha$ line source $(\mathrm{h} v=1486 \mathrm{eV})$, pass energy of $20 \mathrm{eV}$ and resolution of $0.1 \mathrm{eV}$.

\section{Materials}

Iodopentafluorobenzene, poly(4-vinylpyridine) $\left(\mathrm{PVPy}, M_{\mathrm{w}}=6.0 \times 10^{4}\right)$, poly(4-vinylphenol) $(\mathrm{PVPh}$, $\left.M_{\mathrm{w}}=2.0 \times 10^{4}\right)$, poly(acrylic acid) $\left(\mathrm{PAA}, M_{\mathrm{w}}=2.0 \times 10^{3}\right)$ and poly(ethyleneimine) $\left(\mathrm{PEI}, M_{\mathrm{w}}=1.3 \times\right.$ $10^{3}$ ) were purchased from Aldrich. The synthesis of PVPy with different molecular weights was described in ref. 22. 3-aminopropyl-dimethylmethoxysilane was purchased from Acros. Cesium carbonate was purchased from Shanghai Chemical Reagent Company. Azobisisobutyronitrile (AIBN) was recrystallized in methanol. Tetrahydrofuran (THF) was dried with metallic sodium.

Quartz slides and silicon slides were used for the UV-vis, XRR, AFM and XPS measurements. They were all modified with 3-aminopropyl-dimethylmethoxysilane, resulting in $\mathrm{NH}_{2}$-tailored substrates. Agcoated quartz crystal microbalance resonators were dipped in PEI aqueous solution $(1 \mathrm{mg} / \mathrm{mL})$ and PAA aqueous solution $(1 \mathrm{mg} / \mathrm{mL})$ to prepare a 5-layer precursor film of PEI/PAA.

\section{Synthesis of poly(4-(4-iodo-2,3,5,6-tetrafluorophenoxy)-butyl acrylate)}

First, a mixture of iodopentafluorobenzene and excessive amount 1,4-butanediol was refluxed at 80 ${ }^{\circ} \mathrm{C}$ under stirring for $6 \mathrm{~h}$ in the presence of cesium carbonate. The crude product was diluted with water and the organic product was extracted with chloroform. The collected organic layers were dried with sodium sulphate and evaporated. The product 4-(4-iodo-2,3,5,6-tetrafluorophenoxy)butan-1-ol was purified by silica gel column using petroleum ether/ethyl acetate (7:3) as the eluent. Second, acryloyl chloride was slowly dropped into the THF solution of 4-(4-iodo-2,3,5,6-tetrafluorophenoxy)butan-1-ol with triethyl amine at $0{ }^{\circ} \mathrm{C}$. After $10 \mathrm{~h}$ of stirring, the mixture was concentrated and purified by silica gel column using hexane/ethyl acetate $(10: 1)$ as the eluent. ${ }^{1} \mathrm{H}$ NMR for 4-(4-iodo-2,3,5,6tetrafluorophenoxy)-butyl acrylate $\left(\mathrm{CDCl}_{3}, \mathrm{ppm}\right): \delta 4.28,4.24\left(4 \mathrm{H},-\mathrm{O}-\mathrm{CH}_{2}-\right) ; 1.90\left(4 \mathrm{H},-\mathrm{CH}_{2}-\right.$, aliphatic), $6.12(1 \mathrm{H},-\mathrm{CH}=), 5.84\left(1 \mathrm{H}, \mathrm{CH}_{2}=\right.$, trans $) ; 6.41\left(1 \mathrm{H}, \mathrm{CH}_{2}=\right.$, cis $)$.

Polymerization of 4-(4-iodo-2,3,5,6-tetrafluorophenoxy)-butyl acrylate was carried out in anhydrous THF with AIBN at $70{ }^{\circ} \mathrm{C}$ under $\mathrm{N}_{2}$ protection for about 15 hours. Then the solvent was evaporated, and the oily crude product was washed by hexane/ethyl acetate 10:1 for several times. The obtained polymer 
(noted as PIPBA) was dried in vacuum at $45^{\circ} \mathrm{C}$. The average molecular weight is around $5.0 \times 10^{3} .{ }^{1} \mathrm{H}$ NMR for PIPBA $\left(\mathrm{CDCl}_{3}, \mathrm{ppm}\right): \delta 4.11,4.24\left(4 \mathrm{H},-\mathrm{O}-\mathrm{CH}_{2}-\right) ; 1.84\left(4 \mathrm{H},-\mathrm{CH}_{2}-\right.$, aliphatic), 2.29 (-CH-, main chain), $1.67\left(-\mathrm{CH}_{2-}\right.$, main chain). ${ }^{13} \mathrm{C}$ NMR for PIPBA: $\delta 63.9$ (C-I, aromatic); 146.3, 148.3; 139.8, 141.8 (C-F, aromatic), 138.1 (C-O, aromatic), 74.8, 64.1, 26.5, $25.0\left(-\mathrm{CH}_{2}-\right.$, aliphatic), 174.5 (COO-), 41.5, 31.5 (-CH-, $-\mathrm{CH}_{2}-$, main chain), ${ }^{19} \mathrm{~F}$ NMR for PIPBA: $\delta-121.7\left(\mathrm{~F}_{2,6}\right),-154.9\left(\mathrm{~F}_{3,5}\right)$.

XPS curves of PIPBA, PVPy, mixture (ratio $=1: 1)$ and $(P I P B A / P V P y)_{5}$ film
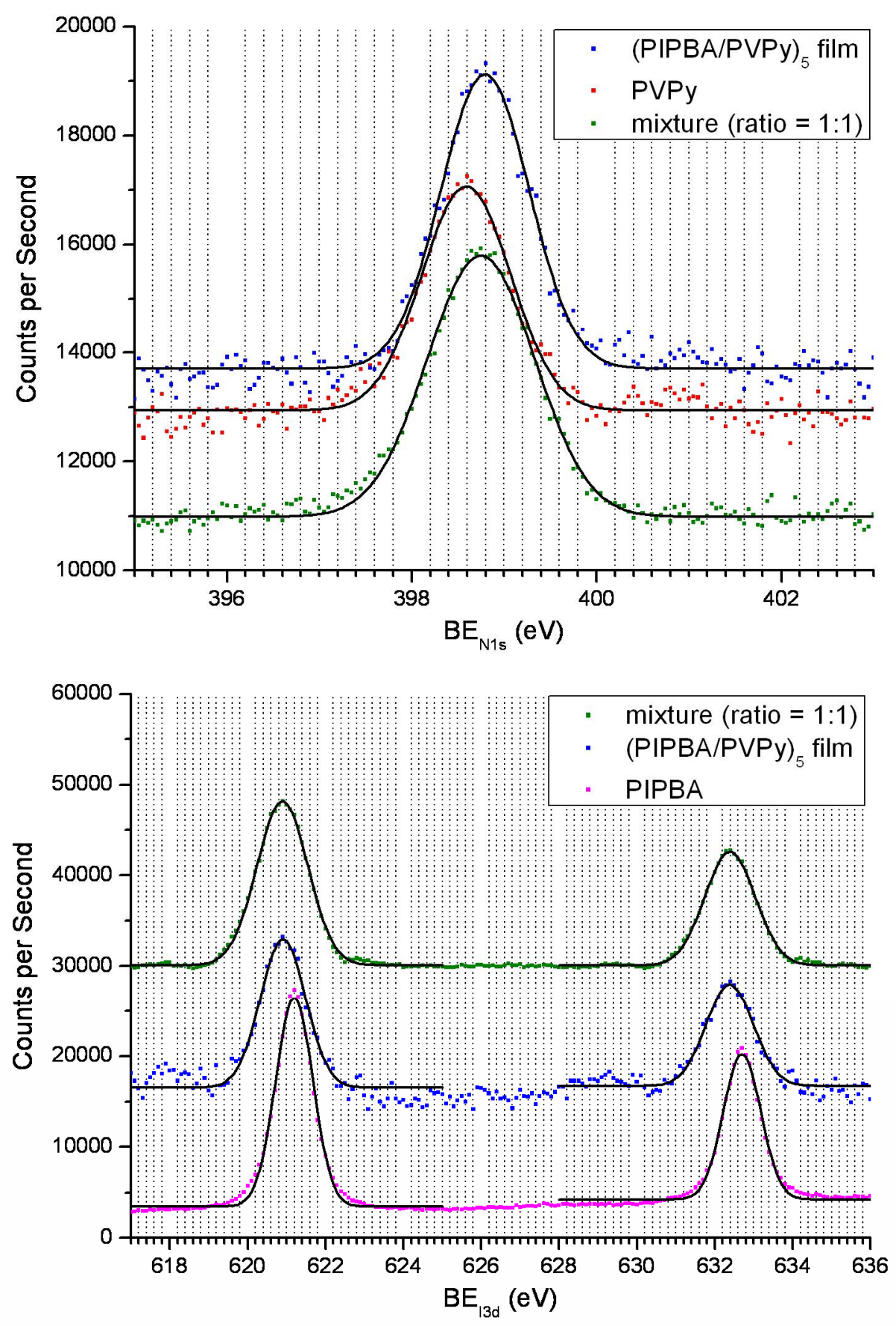

The solid lines are Gauss fit curves of corresponding spectra. 